\title{
Entrepreneurship and Productivity: the Slow Growth of the Planned
}

\section{Economies}

\author{
Claustre Bajona ${ }^{\mathrm{a},{ }^{*}, \text { Luis Locay }^{\mathrm{b}}}$ \\ ${ }^{a}$ Department of Economics, Ryerson University, 350 Victoria Street, Toronto, ON M5B 2K3, Canada \\ ${ }^{\mathrm{b}}$ Department of Economics, University of Miami, 5250 University Drive, Coral Gables, FL 33146, USA
}

\begin{abstract}
:
Trends in gross domestic product (GDP) and total factor productivity (TFP) growth in the former socialist economies seem to indicate that these economies were converging to unusually low long-run growth rates in the late 1980s. In this paper we develop an endogenous growth model of entrepreneurship that is able to account for the difference in long-run performance between centrally planned economies and market-oriented ones. Long-run growth rates of output and productivity are determined by the growth of the stock of managerial knowledge, which in turn depends on the share of the population involved in entrepreneurial activities and on the time that they spend on those activities. We analyze the effect of two characteristics of centrally planned economies on their growth performance. First, in centrally planned economies factors of production are distributed by the central planner to the firms' managers through a contest that uses up some of the managers" productive effort. Second, the leadership is "egalitarian", in the sense that it treats individuals with different abilities equally. We show that these two features reduce the fraction of people becoming entrepreneurs/managers, as well as their managerial effort, which in turn reduces long-run output and TFP growth. Furthermore, we find that centrally planned economies have lower income inequality and slightly higher capital-output ratios, which is consistent with these countries' experiences.
\end{abstract}

JEL codes: O4, P5

Key words: managerial knowledge, productivity, growth, economic systems

\footnotetext{
* Corresponding author.

Fax: +1-416-598-5916

E-mail address: cbajona@miami.edu
} 
...there are a variety of roles among which the entrepreneur's efforts can be reallocated, and some of those roles do not follow the constructive and innovative script that is conveniently attributed to that person ... How the entrepreneur acts at a given time and place depends heavily on the rules of the game - the reward structure in the economy - that happens to prevail.

[Baumol (1990), p. 894]

\section{Introduction}

One of the intriguing aspects of the $20^{\text {th }}$ century's experiments in central planning is the decline over time in the economic performance of socialist economies relative to their more market-oriented, and usually more developed, contemporaries. This economic decline was widespread and significant, and may have contributed to the collapse of the Soviet system (Easterly and Fisher, 1995). Table 1 shows real per capita growth rates for several socialist countries during the postwar period. By the 1980s the Soviet Union's growth rate, computed using both Western estimates of Soviet GNP and official (Soviet) figures of net material product (NMP), was less than half that of the U.S. and falling. ${ }^{1}$ The growth experience of Eastern European countries mimics that of the Soviet Union, but at even lower rates. For the case of Cuba, Madrid-Aris (1997) estimates Cuba's growth rate of gross material product (GMP) per capita in the period 1980-88 to be 2.7 percent, despite Soviet subsidies that had reached 30 percent of GMP by the 1980 s. In the latter half of that period, before the collapse of the Soviet Union and the end of its subsidies, growth had fallen to 0.3 percent.

More importantly for our work, the same pattern of decline is also seen in total factor productivity (TFP) growth. Bergson (1989) calculated that TFP growth for the Soviet Union declined from 1.87 percent in the 1950 s to 1.51 percent in the following decade, 
and 0.11 percent in the period 1970-75. Using Western data Easterly and Fisher (1995) obtain similar results, with TFP growth turning negative at -0.2 percent for the period 1980-87. For Cuba, Madrid-Aris (1997) finds that TFP growth went from 1.0 percent during $1963-70$, to 0.8 percent in $1971-80$, and then fell sharply to -1.7 percent during 1981-88. While it is easy to think of reasons why centrally planned economies should be less productive than market-oriented ones, the apparent convergence of these countries to unusually low long-run growth rates is harder to explain.

In this paper we analyze the effect of central planning on long-run balanced growth paths. We focus on two main characteristics of centrally planned economies that differentiate them from decentralized economies: (i) the lack of decentralized markets for productive inputs, with the leadership (or central planner) acting as the supply mechanism for enterprises (Roberts, 1990), and (ii) the pursuit of policies by the leadership that result in a more egalitarian distribution of income. We consider an endogenous growth framework where the TFP level is a function of the stock of managerial (entrepreneurial) knowledge in the economy which, in turn, is a function of the overall managerial effort. We adapt the model of entrepreneurship in Murphy, Scheifler, and Vishny (1991), which in turn builds on that of Lucas (1978). We consider a model economy with infinite lived individuals who differ in their level of entrepreneurial ability. Individuals with high ability become entrepreneurs, and those with low ability become production workers. In the decentralized framework, the resources that each entrepreneur gets are determined by the market. In the centralized economy, where the government owns and distributes all resources, managers (the equivalent to entrepreneurs in a decentralized society) need to spend time lobbying the central planner to obtain

\footnotetext{
${ }^{1}$ NMP does not include consumer services.
} 
inputs for their enterprises. This reduces the amount of time devoted to productive activities and, thus, reduces output. Even if the government distributes output in an "efficient" way (that is, in a way that distorts individuals' decisions the least, compared to the decentralized economy), the reduction in production effort translates into a reduction in the rate of accumulation in the stock of managerial knowledge. We call this mechanism the "lobbying effect". Furthermore, as centralized economies tend to seek a more egalitarian distribution of income, the behavior of individuals is distorted further by reducing their incentives to become entrepreneurs, reducing managerial effort even more. We call this effect the "redistribution effect".

Our work is related to papers in the literature that deal with the growth patterns of centrally planned economies. Roberts and Rodriguez (1997) analyzes the high growth rates achieved by centrally planned economies in the initial periods. They model the leadership as a self-interested central planner who owns all capital and maximizes a discounted stream of unproductive state consumption. Brixiová and Buliř (2003) explain the growth slowdown of the centrally planned economies as a failure to provide incentives for eliciting high effort from managers of enterprises. These papers differ from ours in several important aspects. First, they focus on different sources of inefficiency created by the leadership. Second, and more importantly, the differences in growth rates between decentralized and centralized economies are simply temporary phenomenon of the transition to new steady states. Both papers are silent about possible long run discrepancies among decentralized and centrally planned economies.

The paper is organized as follows: section 2 presents the decentralized framework and characterizes the balanced growth path of our model economy. Section 3 describes the 
centrally planned economy, characterizes its balanced growth path, and develops a framework for comparing the balanced growth paths of decentralized and centralized economies. In section 4 we calibrate the parameters of the model to U.S. data and compare the generated balanced growth paths for both types of economies. We conclude in section 5 .

\section{The Economy Under Decentralized Decision-Making}

This section introduces the basic framework by modeling the economy under decentralized decision-making. The environment is one of infinite horizon with infinitelylived consumers. There is a measure $N$ of consumers in the economy. Individuals are born with an innate level of entrepreneurial ability, $a$, that is constant over time. The ability level is private information to the individual, with ability levels distributed among the population according to a distribution function $G(a)$ with continuous density $g(a)$ and support $S \subset \mathbb{R}_{+}$. The distribution function is exogenously given and does not change over time. Individuals of ability $a$ are endowed with $k_{0}(a)$ units of capital in the initial period. Individuals are also endowed with one unit of time every period that they can use either in the production of the economy's single good or in lobbying activities.

Following Lucas (1978), we model entrepreneurs as managers of a productive technology that uses capital, raw labor, and the entrepreneur's effort as inputs. Managerial effort is given by $x_{t} \ell a$ where $x_{t}$ is the time the manager spends in productive activities, $a$ is the entrepreneur's entrepreneurial ability, and $\ell$ is the efficiency units of entrepreneurship per unit of time devoted to entrepreneurial activity. The latter is 
exogenously given and common to all entrepreneurs. The production function faced by an entrepreneur of ability $a$ in period $t$ is given by:

$$
y_{t}(a)=\lambda_{t}\left(x_{t} \ell a\right)^{1-\theta}\left[k^{\alpha} n_{t}^{1-\alpha}\right]^{\theta},
$$

where $k_{t}$ is the amount of capital rented by the entrepreneur, $n_{t}$ is the number of workers the entrepreneur employs, and $\lambda_{t}$ is the stock of managerial knowledge (discussed below). The parameters $\alpha$ and $\theta$ satisfy $\alpha, \theta \in(0,1)$. Notice that this production function exhibits constant returns to scale in managerial effort, capital, and labor, but decreasing returns in capital and labor alone.

In our formulation, as in Lucas (1978), the entrepreneur does not own the capital nor have any specific venture that needs to be financed. The entrepreneur is just a manager whose return to managerial effort is equal to the residual profits of operating the productive technology. Therefore, each period entrepreneurs face the static problem of maximizing period returns to managerial effort. Let $r_{t}$ be the rental rate of capital and $w_{t}$ be the wage paid to workers. The entrepreneur chooses how much time to spend in productive activities and how much capital and raw labor to hire in order to maximize profits, $\pi_{t}(a)$. Formally, the entrepreneur solves the problem:

$$
\begin{gathered}
\pi_{t}(a)=\max _{x_{t}, n_{t}, k_{t}}\left\{\lambda_{t}\left(x_{t} \ell a\right)^{1-\theta}\left(k_{t}^{\alpha} n_{t}^{1-\alpha}\right)^{\theta}-w_{t} n_{t}-r_{t} k_{t}\right\} . \\
\text { s.t. } 0 \leq x_{t} \leq 1
\end{gathered}
$$

In the decentralized economy resources are supplied in a competitive market, and there is no benefit from lobbying. Therefore, $x_{t}=1$ for all $t$ and $a$.

Let $\kappa(a)=k(a) / n(a)$ be the capital-labor ratio employed by an entrepreneur of ability $a$. From the first order conditions on the entrepreneur's problem we obtain: 


$$
\kappa_{t}(a)=\kappa_{t} \equiv \frac{\alpha}{1-\alpha} \frac{w_{t}}{r_{t}}
$$

Notice that this capital-labor ratio depends only on the economy's wage-rental ratio and not on the entrepreneur's ability. Therefore, all entrepreneurs use the same capital-labor ratio in any given period. From here, we obtain the amount of capital and labor hired by each entrepreneur:

$$
\begin{aligned}
& k_{t}(a)=\lambda_{t}^{1 /(1-\theta)} \ell a \kappa_{t}^{1-\alpha} \Delta_{t} \\
& n_{t}(a)=\lambda_{t}^{1 /(1-\theta)} \ell a \kappa_{t}^{-\alpha} \Delta_{t},
\end{aligned}
$$

where $\Delta_{t}=\left[\theta\left(\alpha / r_{t}\right)^{\alpha} /\left((1-\alpha) / w_{t}\right)^{1-\alpha}\right]^{\frac{1}{1-\theta}}$ is a function of the input prices. The output and profits produced by an entrepreneur of ability $a$ are given by:

$$
y_{t}(a)=\lambda_{t}^{1 /(1-\theta)} \ell a \Delta_{t}^{\theta}
$$

and

$$
\pi_{t}(a)=(1-\theta) y_{t}(a)
$$

Notice that the resources used and output produced by an entrepreneur of ability $a$ relative to an entrepreneur of ability $a^{\prime}$ are given by:

$$
\frac{y_{t}(a)}{y_{t}\left(a^{\prime}\right)}=\frac{k_{t}(a)}{k_{t}\left(a^{\prime}\right)}=\frac{n_{t}(a)}{n_{t}\left(a^{\prime}\right)}=\frac{a}{a^{\prime}} .
$$

That is, the quantity of output produced by a firm is directly related to the ability level of its manager.

Individuals in this economy derive utility from consumption of the economy's single good. Their preferences are represented with a CES period utility function $u(c)=\left(c^{\sigma}-1\right) / \sigma$. Every period they choose their occupation (worker or entrepreneur), consumption, and savings in order to maximize the present discounted value of their 
utility. All savings in the economy are done by accumulating capital. The problem faced by an individual with ability $a$ is:

$$
\begin{array}{ll}
\max _{e_{t}, c_{t}, b_{t+1}} \sum_{t=0}^{\infty} \beta^{t} u\left(c_{t}(a)\right) \\
\text { s.t. } & c_{t}(a)+b_{t+1}(a)=e_{t} \pi_{t}(a)+\left(1-e_{t}\right) w_{t}+\left(1+r_{t}^{b}\right) b_{t}(a), \\
& 0 \leq e_{t} \leq 1
\end{array}
$$

where $c_{t}$ is consumption, $b_{t}$ is savings, $r_{t}^{b}$ is the interest rate, $e_{t}$ is the fraction of time devoted to each occupation in period $t$, and $\beta \in(0,1)$ is the discount factor.

From the first order conditions of the consumer we obtain:

$$
\frac{c_{t}(a)}{c_{t+1}(a)}=\left[\beta\left(1+r_{t+1}^{b}\right)\right]^{1 /(\sigma-1)}
$$

This ratio is also independent of the ability of the consumer: the marginal rate of substitution between consumption at different points in time is the same for all consumers.

The occupational choice of the individual is straightforward: at every period $t$ an individual of ability $a$ chooses to be a worker $\left(e_{t}=0\right)$ or an entrepreneur $\left(e_{t}=1\right)$ according to which activity yields the highest income. ${ }^{2}$ Let $\tilde{a}_{t}$ be the ability of an individual in period $t$ who is indifferent between being an entrepreneur or a worker. Given that entrepreneurs' profits are an increasing function of their ability, all individuals with ability level below the threshold $\tilde{a}_{t}$ become workers and all individuals with ability level above the threshold become entrepreneurs. Using (6) the threshold $\tilde{a}_{t}$ can be written as: 


$$
\tilde{a}_{t}=\frac{w_{t}}{(1-\theta) \lambda_{t}^{1 /(1-\theta)} \Delta_{t}^{\theta} \ell}
$$

Given the threshold $\tilde{a}_{t}$, the total supply of laborers in period $t$ is equal to $N G\left(\tilde{a}_{t}\right)$. By aggregating production and demand for inputs over all entrepreneurs we obtain the aggregate output and input demands. Let us define $\tilde{S}_{t}=\left\{a \in A \mid a \geq \tilde{a}_{t}\right\}$ to be the set of ability levels of practicing entrepreneurs and $M\left(\tilde{a}_{t}\right)=\int_{\tilde{S}_{t}} a d G(a)$ as the average entrepreneurial ability of practicing entrepreneurs. By integrating over all entrepreneurs, the demands for raw labor and capital at period $t$ are given by:

$$
\begin{aligned}
& L_{t}^{d}=N \lambda_{t}^{1 /(1-\theta)} \ell \Delta_{t} M\left(\tilde{a}_{t}\right) \kappa_{t}^{-\alpha} \\
& K_{t}^{d}=N \lambda_{t}^{1 /(1-\theta)} \ell \Delta_{t} M\left(\tilde{a}_{t}\right) \kappa_{t}^{1-\alpha},
\end{aligned}
$$

and the level of output is given by:

$$
Y_{t}=\lambda_{t}^{1 /(1-\theta)} \ell \Delta_{t}^{\theta} M\left(\tilde{a}_{t}\right) N .
$$

The single good produced in the economy is used for both consumption and investment in new capital. The supply of capital is given by:

$$
K_{t}^{s}=N \int_{S} b_{t}(a) d G(a) .
$$

Non-arbitrage opportunities imply that the returns on savings have to be equal to the rental rate of capital, net of depreciation:

$$
r_{t}^{b}=r_{t}-\delta
$$

In equilibrium both the labor and the capital markets clear:

$$
L_{t}^{d}=N G\left(\tilde{a}_{t}\right),
$$

\footnotetext{
${ }^{2}$ Individuals that are indifferent between becoming workers or entrepreneurs may split their time among both activities. They represent a set of measure zero and, therefore, their decision does not affect our
} 
and

$$
K_{t}^{d}=K_{t}^{s}
$$

The market for the single good in the economy has to clear as well. That is, total expenditure equals total output:

$$
C_{t}+K_{t+1}-(1-\delta) K_{t}=Y_{t}
$$

where $C_{t}=N \int_{S} c_{t}(a) d G(a)$ is the economy's aggregate consumption.

Finally, we need to explain how the stock of managerial knowledge $\lambda_{t}$ changes over time. Following Murphy, Scheifler, and Vishny (1991), the change in the level of the stock of managerial knowledge depends on current entrepreneurial practice. ${ }^{3}$ In particular, we assume that the parameter $\lambda_{t}$ depends on the mean managerial effort of the entire population, with workers receiving zero weight because they devote no time to

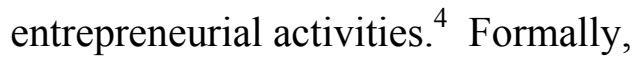

$$
\lambda_{t+1}-\lambda_{t}=\gamma \lambda_{t} \ell \int_{\tilde{S}_{t}} \operatorname{adG}(a)-\mu \lambda_{t}
$$

where $\gamma$ is a parameter and $\mu$ is the rate of depreciation of managerial knowledge. With this formulation, given a distribution of ability $G(a), \lambda_{t}$ will grow more rapidly the greater the fraction of the population that are entrepreneurs (the smaller is $\tilde{a}_{t}$ ). Entrepreneurial activity provides a positive technological externality in this model, generating perpetual growth.

results. For simplicity, here we assume that they decide to become full-time entrepreneurs $\left(e_{t}=1\right)$.

${ }^{3}$ In Murphy, Scheifler, and Vishny (1991) $\lambda_{t}$ takes on the value of the previous period's "best practice", which is simply the ability of the entrepreneur with highest ability.

${ }^{4}$ An alternative formulation would be $\lambda_{t+1}-\lambda_{t}=\gamma \lambda_{t} \int_{\tilde{S}_{t}} a \ell\left(d G(a) / 1-G\left(\tilde{a}_{t}\right)\right)-\mu \lambda_{t}$. Here the rate of growth of $\lambda_{t}$ depends on the mean managerial effort of entrepreneurs only. 
Definition 1. Given a distribution of initial capital stocks, $\left\{k_{0}(a)\right\}$, a competitive equilibrium for the economy described above is a set of sequences: consumption, savings, and occupational choice for each ability level for each period, $\left\{c_{t}(a), b_{t+1}(a), e_{t}(a)\right\}$, prices, $\left\{r_{t}^{b}, r_{t}, w_{t}\right\}$, a threshold separating workers from entrepreneurs, $\left\{\tilde{a}_{t}\right\}$, entrepreneurial choices, $\left\{y_{t}(a), k_{t}(a), n_{t}(a), x_{t}(a)\right\}$, and technology levels, $\left\{\lambda_{t}\right\}$, such that:

(i) Given prices and technology levels, $\left\{c_{t}(a), b_{t+1}(a), e_{t}(a)\right\}$ solve the consumer's problem (8).

(ii) Given prices and technology levels, entrepreneurial choices $\left\{y_{t}(a), k_{t}(a), n_{t}(a), x_{t}(a)\right\}$ solve the profit maximization problem (2).

(iii) Given prices and technology levels, $\tilde{a}_{t}$ solves (10).

(iv) Feasibility conditions (15)-(17) are satisfied.

(v) The technology level $\lambda_{t}$ evolves according to the law of motion in (18).

The set of equations that characterize equilibrium for this economy is listed in the Appendix.

The next proposition derives properties of the occupational threshold $\tilde{a}_{t}$. It states that, given our assumptions on functional forms, the value of the occupational threshold is constant over time, and it depends only on the distribution of abilities and the input shares in production. 
Proposition 1. For any distribution of abilities $G(a)$ satisfying the assumptions described above, the occupational threshold is unique and constant over time. It is defined implicitly by the equation:

$$
\frac{\tilde{a} G(\tilde{a})}{M(\tilde{a})}=\frac{\theta(1-\alpha)}{1-\theta} .
$$

Proof: The equation follows from (10), (11) and (15). Existence and uniqueness follows from the fact that the left hand side is continuous and strictly increasing in $\tilde{a}$, takes the value 0 for $\tilde{a}=\inf S$ and converges to infinity as $\tilde{a}$ converges to $\sup S$

The result obtained in proposition 1 highly simplifies the solution of the model. Even though this model involves heterogeneous agents, for any given occupational threshold $\tilde{a}$ the equilibrium prices and aggregate variables in this model are equivalent to the equilibrium prices and aggregate variables of a representative agent's problem with a single type of producer. Therefore, after solving for $\tilde{a}$ using (19), solving for the aggregate variables of the model reduces to solving a representative agent problem. The next proposition states this result formally. The proof can be found in the Appendix.

Proposition 2. Assume that there exists an equilibrium of our model economy and let $\tilde{a}$ be that equilibrium's occupational threshold. Then, the equilibrium prices and aggregate variables of our model economy are also the equilibrium solution of an economy with the same characteristics but with a representative consumer and a single producer (who 
takes the evolution of $\lambda_{t}$ as exogenously given and behaves competitively) that uses the technology

$$
Y_{t}=A_{t}\left[K_{t}^{\alpha} L_{t}^{1-\alpha}\right]^{\theta}
$$

where $A_{t}=\lambda_{t}(M(\tilde{a}) N \ell)^{1-\theta}$.

From the first order conditions of the representative consumer's problem we obtain an expression of the rental rates of capital and labor in terms of the aggregate variables:

$$
\begin{aligned}
& r_{t}=\alpha \theta A_{t} K_{t}^{\alpha \theta-1} H^{(1-\alpha) \theta} \\
& w_{t}=(1-\alpha) \theta A_{t} K_{t}^{\alpha \theta} H^{(1-\alpha) \theta-1},
\end{aligned}
$$

where $H=N G(\tilde{a})$. This formulation will be useful in comparing the solution of the decentralized economy to the centrally planned economy that we describe in section 4 .

\subsection{Balanced growth in the decentralized economy}

In this section we investigate the behavior of balanced growth paths in the decentralized economy. We define a balanced growth path as an equilibrium where all variables are either constant or grow at the same rate over time. From the equilibrium conditions listed in the Appendix, in a balanced growth path productivity grows at a rate $\lambda=\gamma \ell M(\tilde{a})-\mu$, with $\lambda_{t}=(1+\lambda)^{t} \lambda_{0}$, whereas aggregate output, consumption, capital and wage rates grow at the rate $\eta=(1+\lambda)^{1 /(1-\alpha \theta)}-1$. Notice that both growth rates depend on the ability threshold $\tilde{a}$ and on the efficiency parameter $\ell$. 
Given the nature of our production functions, the balanced growth path can be solved analytically as a function of the equilibrium threshold. The interest rate in the balanced growth path is given by:

$$
r^{b}=\frac{(1+\eta)^{1-\sigma}}{\beta}-1,
$$

and the wage rate is $w_{t}=(1+\eta)^{t} w_{0}$, where

$$
w_{0}=(1-\alpha)(1+\eta)\left[\frac{\theta^{1 /(1-\theta)} \ell M(\tilde{a})}{G(\tilde{a})}\right]^{(1-\theta) /(1-\alpha \theta)}\left(\frac{\alpha}{r_{0}}\right)^{\alpha \theta /(1-\alpha \theta)},
$$

and $r_{0}=r^{b}+\delta$. The rest of the equilibrium variables can be easily derived as functions of the interest rate and the wage by using the equilibrium conditions listed in the Appendix.

\subsection{Sources of growth in the decentralized economy}

In what follows we use growth accounting techniques to decompose the growth rate of output into the portion due to factor accumulation, and the portion due to total factor productivity growth. It is the latter that we are interested in measuring.

Taking logs in equation (20) and comparing the value of the log of output between two consecutive periods, we obtain the growth accounting equation:

$$
\bar{y}_{t+1}-\bar{y}_{t}=\left[\bar{\lambda}_{t+1}-\bar{\lambda}_{t}\right]+(1-\alpha \theta)\left(\bar{N}_{t+1}-\bar{N}_{t}\right)+\alpha \theta\left(\bar{K}_{t+1}-\bar{K}_{t}\right),
$$

where $\bar{v}=\log v$ for any generic variable $v$.

The right hand side of the equation shows the contribution of changes in total factor productivity, labor, and capital, to output growth. We observe that each percentage increase in the labor force contributes $1-\alpha \theta$ percentage points to output growth. The 
corresponding number for capital is $\alpha \theta$. Notice that the weights corresponding to the growth rates of capital and the labor force add up to one, just as if the aggregate production function exhibited constant returns to scale in capital and labor. The term in brackets on the right hand side of (24) represents growth in total factor productivity. Along a balanced growth path this term becomes $\gamma \ell M(\tilde{a})-\mu$, which is increasing in managerial effort and decreasing in the value of the ability threshold $\tilde{a}$. We can conclude, therefore, that raising entrepreneurial activity by either increasing the managerial effort of each entrepreneur or by increasing the fraction of the population that become entrepreneurs, increases growth.

\section{The Centrally Planned Economy}

In autocratic societies where the top leadership has considerable control over the allocation of resources, one would expect such a leadership to be quite interested in efficiency. Olson (1982) refers to such leaders as having an "encompassing interest," for they can capture and allocate much of an economy's output. The ability to capture much or all of an economy's total output, however, is not enough to achieve efficiency. One difficulty is that the top leadership has to delegate much of the entrepreneurial and managerial functions to others (even more so for the top leader). In particular, the leadership has the responsibility of distributing resources among managers, whose managerial ability is hard to assess. Furthermore, the leadership of centrally planned economies tends to pursue policies that result in more egalitarian distributions of 
income. ${ }^{5}$ In what follows we modify the framework of the previous section in order to account for these two features of centrally planned economies.

The basic structure of the model remains the same as in the decentralized economy: people are born with an exogenous level of entrepreneurial ability and they decide whether to use their ability and become managers of the production technology or not to use it and work as laborers. The main difference between both arrangements is the introduction of the leadership in the centrally planned economy. The leadership owns the capital stock and receives all production in the economy, which it distributes between investment and consumption goods to be delivered to the country's consumers. As in Roberts and Rodriguez (1997), we assume that there is no storage technology and individuals cannot borrow and lend from each other. ${ }^{6}$ Therefore, in each period individuals consume all the income distributed to them by the leadership.

The timing of the decision making in the centrally planned economy works as follows: at the beginning of each period $t$ the leadership announces a compensation scheme to be delivered at the end of the period. The structure of the compensation scheme used by the leadership is such that it pays a fixed amount of goods, $\bar{m}_{t}$, to all individuals who work as laborers in period $t$ and compensates managers depending on their production level: a manager who produces output $y_{t}$ in period $t$ receives

\footnotetext{
${ }^{5}$ It does not matter for our purposes whether a more egalitarian society was the leadership's ultimate aim, or simply a means by which to maintain political support.

${ }^{6}$ Given that there is no uncertainty in this model and the leadership is a benevolent planner, this assumption is not restrictive. Roberts and Rodriguez (1997) state that savings in centrally planned economies were mainly used "to finance the purchase of expensive consumer durables ... and ... goods appearing unexpectedly on the market", instead of a consumption smoothing device. Furthermore, any savings were done through state banks, which distributed the capital among the state firms.
} 
compensation $m_{t}=\bar{\tau}_{t} y_{t} \cdot{ }^{7}$ Furthermore, we assume the existence of a perfect commitment mechanism, so that the leadership cannot change previously announced policies. ${ }^{8}$ Once the compensation scheme is announced individuals make their occupational choices and managers decide how much of each input to hire and how much time to spend in lobbying activities.

\subsection{Individuals’ decisions}

Given our assumptions on borrowing and lending, individuals face a static occupational decision every period. As in the decentralized economy, individuals who become workers devote their unit of time to working as laborers. The problem of the managers is more complicated than in the decentralized economy. In the centrally planned economy, managers cannot rely on the market to obtain their inputs, and have to get them directly from the leadership, through lobbying. The leadership cannot distinguish a manager's ability ex-ante and, thus, it holds a contest in which resources are distributed according to the manager's lobbying efficiency. Studies of management in the USSR during the socialist period emphasize the procurement of inputs as the managers' main worry. Two features of the system contributed to this. First, the need of allocation orders in order to be entitled to receive inputs. Berliner (1957) characterizes the procurement of these documents as the focus of "much of the activity of management" (p.22). Allocation

\footnotetext{
${ }^{7}$ This compensation scheme would be optimal in a more generalized framework where the leadership could not infer the manager's ability. It ensures that individuals are going to reveal their true ability level, that managers are going to maximize their production, and that only the most able individuals become managers.

${ }^{8}$ It is well known that commitment is a problem in any framework that involves government policy in an intertemporal setting. We make the assumption in order to avoid time-inconsistency problems. A possible motivation is to assume that failure to deliver pre-announced compensations would cause revolt, potentially leading to the fall of the government.
} 
orders were distributed according to the firm's annual economic plan which, in turn, was determined through a long bargaining process between managers and government officials. According to Berliner (1999), during the months when the annual economic plans were designed (the first three months of the year) managers “...descended on Moscow in great profusion... working to 'beat out' more favorable conditions for their enterprises. Management's influence with ministry officials went a long way in getting plan assignments and input authorizations that were favorable to the enterprise.” (p. 250). Second, there was a "perpetual shortage of supplies" (Berliner 1957, p. 24) that implied that even the possession of an allocation order did not guarantee that the inputs would be delivered. Further bargaining and the "extensive use of personal influence" (Berliner 1976, p 72) was needed in order to ensure a flow of resources to a manager's enterprise.

In our model, the lobbying efficiency of a manager depends on the fraction of the time he spends lobbying, as well as on his ability, and on the total lobbying efficiency in the economy. We assume that the more able managers are also better lobbyists, which implies that the distribution of resources among managers in the centrally planned economy is very similar to the one in the decentralized economy. ${ }^{9}$

Let $z(a)$ be the fraction of the available capital and raw labor in a given period obtained by a manager with ability level $a$, who spends $1-x$ of his time in lobbying activities. Then:

$$
z(a)=\frac{(1-x) a}{v}
$$

\footnotetext{
${ }^{9}$ A more general version of the model which distinguishes between managerial and lobbying abilities is presented in the appendix.
} 
where $v=N \int_{S}(1-x(a)) a d G(a)$ is the total efficiency units of lobbying. ${ }^{10}$ Here we assume that $x(a)=1$ for all laborers. A manager of ability $a$ chooses a production effort level $x$ so as to maximize his utility, taking the compensation scheme as given. In our set-up, this is equivalent to maximizing his production level. Formally, the manager solves the maximization problem:

$$
\max _{x_{t}}\left\{\bar{\tau}_{t} \lambda_{t}\left(x_{t} \ell a\right)^{1-\theta}\left[z_{t}(a) K_{t}\right]^{\alpha \theta}\left[z_{t}(a) H_{t}\right]^{(1-\alpha) \theta}\right\}
$$

where $H_{t}$ is the amount of labor available in the economy.

Using the expression for $z(a)$ derived in $(25)$ the manager's problem becomes:

$$
\begin{aligned}
& \max _{x_{t}} B_{t} a x_{t}^{1-\theta}\left(1-x_{t}\right)^{\theta}, \\
& \text { s.t. } \quad 0 \leq x_{t} \leq 1
\end{aligned}
$$

where $B_{t}=\bar{\tau}_{t} \lambda_{t} \ell^{1-\theta} K_{t}^{\alpha \theta} H_{t}^{(1-\alpha) \theta} / v_{t}^{\theta}$. The solution to this problem is $x_{t}=1-\theta$ for all $t$.

That is, the effort level devoted to production is homogeneous across managers and over time. Therefore, the income received by a manager with ability a depends linearly on his ability level and it is given by $m_{t}(a)=B_{t} a(1-\theta)^{1-\theta} \theta^{\theta}$.

Given the compensation scheme designed by the leadership, there is also an occupational threshold in the centrally planned economy, $\bar{a}_{t}$, so that all individuals with ability levels above the threshold become managers. The threshold is determined by the ability level that receives the same income in any of the two occupational choices, and it is implicitly defined by the equation:

$$
\bar{m}_{t}=B_{t} \bar{a}_{t}(1-\theta)^{1-\theta} \theta^{\theta}
$$

\footnotetext{
${ }^{10}$ This is a special case of the widely used ratio form of the contest success function. See Hirshleifer (1989) and Baik (1998) for a comparison with other forms.
} 
Notice that since all managers choose to use the same fraction of time $\theta$ in lobbying activities, the fraction of resources that a manager of ability a obtains for production is:

$$
z_{t}(a)=\frac{a}{N M\left(\bar{a}_{t}\right)}
$$

which is linear in his ability level.

The output produced by a manager of ability $a$ in period $t$ can be written as a function of aggregate variables in the following way:

$$
y_{t}(a)=\lambda_{t} a(1-\theta)^{1-\theta} \ell^{1-\theta} \frac{K_{t}^{\alpha \theta} H_{t}^{(1-\alpha) \theta}}{N^{\theta} M(\bar{a})^{\theta}},
$$

where $H_{t}=N G(\bar{a})$ is constant over time. Using this expression we can rewrite (28) as

$$
\frac{\bar{a}_{t}}{\left(M\left(\bar{a}_{t}\right)\right)^{\theta}}=\frac{\bar{m}_{t} N^{\theta}}{\bar{\tau}_{t}(1-\theta)^{1-\theta} \ell^{1-\theta} \lambda_{t} K_{t}^{\alpha \theta} H^{(1-\alpha) \theta}} .
$$

Notice that under this distribution scheme the resources received by an entrepreneur of ability $a$ relative to the resources received by an entrepreneur of ability $a^{\prime}$ as well as their relative level of output satisfy $y_{t}(a) / y_{t}\left(a^{\prime}\right)=z_{t}(a) / z_{t}\left(a^{\prime}\right)=a / a^{\prime}$, which is exactly the same ratio as in the decentralized economy. Therefore, the leadership in this framework distributes resources among entrepreneurs efficiently: it does not value relative entrepreneurial ability differently than the market. Redistribution in the centrally planned economy takes place between workers and entrepreneurs, but not within entrepreneurs. This result depends crucially on the fact that we do not distinguish between managerial and lobbying abilities. ${ }^{11}$ A more generalized framework that allowed for these two abilities to differ would introduce a new inefficiency in the 
centrally planned economy: misallocation of resources across managers with different managerial abilities. In particular, high ability managers with low lobbying skills would receive less resources than in the efficient allocation. Recent literature suggests that this misallocation of resources has potentially large effects on TFP (see, for instance, Hsieh and Klenow 2007, Restuccia and Rogerson 2007, and the studies cited there in). For simplicity, we abstract from this type of inefficiency in the paper and we outline a more general framework in the last part of the appendix.

\subsection{Leadership's decisions}

We model the leadership as a planner whose objective is to choose a compensation scheme $\left\{\bar{m}_{t}, \bar{\tau}_{t}\right\}_{t=0}^{\infty}$ in order to maximize a social welfare function where each person is given equal weight, regardless of their level of ability. Furthermore, we assume that the leadership does not internalize the effect of lobbying on the growth of managerial knowledge. That is, the leadership takes $\lambda_{t}$ as exogenously given.

The leadership's social welfare function is:

$$
W=N \int_{S}\left[\sum_{t=0}^{\infty} \beta^{t} u\left(c_{t}(a)\right)\right] d G(a)
$$

where $c_{t}(a)$ is the consumption level of an individual with ability $a$ in period $t$, This welfare function reflects our assumption of leadership that behaves as if it was egalitarian, since it equally weights all individuals in the economy, independently of their ability.

\footnotetext{
${ }^{11}$ We thank an anonymous referee for pointing this out to us.
} 
As we mentioned above, the leadership chooses a compensation scheme $c_{t}(a)=\bar{m}_{t}$ for individuals who work as laborers, and $c_{t}(a)=\bar{\tau}_{t} y_{t}(a)$ for individuals with ability $a$ who work as managers. In our set-up the leadership, by solving the manager's problem, can infer a manager's ability from the amount of resources that he receives during the lobbying process. Therefore, given that a manager's output is linear with respect to his ability level, our compensation scheme is equivalent to one in which a manager's compensation is a linear function of his revealed ability. Due to the fact that individuals do not have incentives to misrepresent their ability, a manager's compensation is a linear function of his own ability. Let us redefine the compensation scheme as follows. The leadership assigns resources $m_{t}(a)$ to an individual of ability $a$ such that:

$$
m_{t}(a)=\left\{\begin{array}{ll}
m_{t} & \text { if } a \leq \bar{a}_{t} \\
\tau_{t} a & \text { if } a>\bar{a}_{t}
\end{array},\right.
$$

where $\bar{a}_{t}$ is the threshold that separates managers from workers, $m_{t}=\bar{m}_{t}$, and $\tau_{t}=\bar{\tau}_{t} \lambda_{t}(1-\theta)^{1-\theta} \ell^{1-\theta}\left(K_{t}^{\alpha \theta} H_{t}^{(1-\alpha) \theta} / N^{\theta} M\left(\bar{a}_{t}\right)^{\theta}\right)$. Using this simplification we can write the leadership's problem as:

$$
\begin{array}{ll}
\max _{m_{t}, \tau_{t}, K_{t+1}} \int_{S} \sum_{t=0}^{\infty} \beta^{t} N u\left(m_{t}(a)\right) d G(a) \\
\text { s.t. } \\
\left.\qquad \begin{array}{l} 
\\
\quad
\end{array} m_{t} G\left(\bar{a}_{t}\right)+\tau_{t} M\left(\bar{a}_{t}\right)\right]+K_{t+1}-(1-\delta) K_{t}=Y_{t} \\
& Y_{t}=\lambda_{t}(1-\theta)^{1-\theta} \ell^{1-\theta} N^{1-\theta} M\left(\bar{a}_{t}\right)^{1-\theta} K_{t}^{\alpha \theta} H_{t}^{(1-\alpha) \theta} \\
& H_{t}=N G\left(\bar{a}_{t}\right) \\
& \bar{a}_{t}=m_{t} / \tau_{t} .
\end{array}
$$

Notice that in this set-up the leadership does not sort out people into workers and managers. The leadership, though, takes into account that people's occupational 
decisions are determined by the payoff scheme that it implements, as stated by the last constraint. The objective function in the problem above can, then, be written as:

$$
\max _{m_{t}, \tau_{t}, K_{t+1}} \sum_{t=0}^{\infty} \beta^{t} N\left[u\left(m_{t}\right) G\left(\bar{a}_{t}\right)+\int_{\bar{S}_{t}} u\left(\tau_{t} a\right) d G(a)\right] .
$$

Let $\varsigma_{t}$ be the Lagrange multiplier for the period- $t$ resource constraint equation. The first order conditions for the problem in (34) are:

$$
\begin{gathered}
\varsigma_{t}=\frac{\beta^{t}\left[\bar{a}_{t} u^{\prime}\left(m_{t}\right) G\left(\bar{a}_{t}\right)+\int_{\bar{S}_{t}} u^{\prime}\left(\tau_{t} a\right) \operatorname{ad} G(a)\right]}{\bar{a}_{t} G\left(\bar{a}_{t}\right)+M\left(\bar{a}_{t}\right)}, \\
\beta^{t} N u^{\prime}\left(m_{t}\right) G\left(\bar{a}_{t}\right)-\varsigma_{t}\left[N G\left(\bar{a}_{t}\right)-\frac{g\left(\bar{a}_{t}\right) Y_{t}}{\tau_{t}}\left(\frac{\theta(1-\alpha)}{G\left(\bar{a}_{t}\right)}-(1-\theta) \frac{\bar{a}_{t}}{M\left(\bar{a}_{t}\right)}\right)\right]=0 \\
\frac{\varsigma_{t}}{\varsigma_{t+1}}=1-\delta+\alpha \theta \frac{Y_{t+1}}{K_{t+1}}
\end{gathered}
$$

which together with the leadership's budget constraint in (34), the relationship $\bar{a}_{t}=m_{t} / \tau_{t}$, and the equation for the evolution of the factor $\lambda_{t}$, characterize the solution to the leadership's problem.

The next proposition compares the equilibrium threshold levels of the decentralized and the centrally planned economies, $\tilde{a}$ and $\bar{a}_{t}$, respectively. It states that at any point in time the threshold level for the centrally planned economy is higher than the threshold level in the decentralized economy, indicating that the centrally planned economy has fewer managers than the decentralized economy.

Proposition 3: Let $\left\{\bar{a}_{t}\right\}$ denote the sequence of equilibrium threshold levels of the centrally planned economy and a be the equilibrium threshold level of the decentralized economy. Then $\bar{a}_{t}>\tilde{a}$. 
The proof relies on the fact that the term in parentheses in equation (37) is decreasing and it is equal to zero for $\bar{a}_{t}=\tilde{a}$. The combination of the first two terms in the equation is positive for all $\bar{a}_{t} \leq \tilde{a}$. Therefore, if there is a solution to the equation, it has to satisfy $\bar{a}_{t}>\tilde{a}$. The details of the proof are in the Appendix.

\subsection{Balanced growth in the centrally planned economy}

The balanced growth assumption implies that the technology level grows at a constant rate $\lambda_{c}=\gamma(1-\theta) \ell M(\bar{a})-\mu$. All other variables grow at the rate $\eta_{c}=\left(1+\lambda_{c}\right)^{1 /(1-\alpha \theta)}-1 .^{12}$ The long run growth rate of the centrally planned economy differs from the growth rate of the decentralized economy in two aspects: a new term, $1-\theta$, and a different threshold level $\bar{a}$. The former is linked to the fact that entrepreneurs need to spend a fraction of their time lobbying for resources (the "lobbying effect"), while the latter is driven by the differences between compensation schemes in both economies (the "redistribution effect"). Both differences produce a lower growth rate in the centrally planned economy. In the next section we address the question of isolating these two effects. We construct a "weighted centrally planned economy" that does not have a redistribution effect and, therefore, all its differences from the decentralized economy are attributed to the lobbying effect. The main intuition for this construction comes from the fact that the occupational threshold $\bar{a}$ is directly linked to the weight that the leadership gives to

\footnotetext{
12 Given the constant elasticity of substitution assumption in utility, the conditions that characterize equilibrium are consistent with the balanced growth assumptions.
} 
individuals of different ability. Therefore, the key is to find a suitable set of weights for which in equilibrium $m_{t} / \tau_{t}=\tilde{a}$.

\subsection{A weighted centrally planned economy}

Let us consider a version of the centrally planned economy where the leadership weights individuals differently depending on their abilities. Let $\varphi(a)$ denote the weight that the leadership gives to an individual with entrepreneurial ability $a$. The welfare function that the leadership faces is now:

$$
W=N \int_{S}\left[\varphi(a) \sum_{t=0}^{\infty} \beta^{t} u\left(c_{t}(a)\right)\right] d G(a) .
$$

Conditions (36) and (37) now become:

$$
\begin{gathered}
\varsigma_{t}=\frac{\beta^{t}\left[\bar{a}_{t} u^{\prime}\left(m_{t}\right) \int_{S \mid \bar{S}_{t}} \varphi(a) d G(a)+\int_{\bar{S}_{t}} \varphi(a) u^{\prime}\left(\tau_{t} a\right) a d G(a)\right]}{\bar{a}_{t} G\left(\bar{a}_{t}\right)+M\left(\bar{a}_{t}\right)}, \\
\beta^{t} N u^{\prime}\left(m_{t}\right) \int_{S \mid \bar{S}_{t}} \varphi(a) d G(a)-\varsigma_{t}\left[N G\left(\bar{a}_{t}\right)-\frac{g\left(\bar{a}_{t}\right) Y_{t}}{\tau_{t}}\left(\frac{\theta(1-\alpha)}{G\left(\bar{a}_{t}\right)}-(1-\theta) \frac{\bar{a}_{t}}{M\left(\bar{a}_{t}\right)}\right)\right]=0 .
\end{gathered}
$$

The two previous equations show that the thresholds $\bar{a}_{t}$ are directly linked to the weights given to each individual by the leadership. Intuitively, the higher the weight given to low ability individuals, the higher the compensation level given to workers and, therefore, the higher the threshold values $\bar{a}_{t}$. By changing the weights that the planner assigns to people with different abilities, we can obtain different threshold values. The next proposition derives a set of weights under which the threshold values of the centrally planned economy coincide with the threshold value of the decentralized economy. Under this specific set of weights, the leadership's distribution scheme mimics the equilibrium 
distribution of income of a modified decentralized economy with efficiency parameter $\hat{\ell}=(1-\theta) \ell$. In this case, the only difference between the two economies comes from the reversion of productive time towards lobbying that managers have to incur in the centrally planned economy, thus isolating the lobbying effect.

Proposition 4: Consider a modified decentralized economy where one unit of entrepreneurial time translates into $\hat{\ell}=(1-\theta) \ell$ efficiency units of managerial effort. Let $v$ denote a generic variable from the balanced growth path equilibrium of such economy. Let $\hat{c}_{0}$ and $\hat{m}_{0}$ be, respectively, the average consumption and the average income per person in such equilibrium. Let $\tau=w_{0} \hat{c}_{0} / \tilde{a} \hat{m}_{0}$ and $m=w_{0}$ and define the weights $\varphi(a)$ as:

$$
\varphi(a)=\left\{\begin{array}{cc}
1 / u^{\prime}(m) \equiv \varphi_{m} & \text { for } a \leq \tilde{a} \\
1 / u^{\prime}(\tau a) & \text { for } a>\tilde{a} .
\end{array}\right.
$$

Then the balanced growth path of the centrally planned economy with weights $\varphi(a)$ coincides with the balanced growth path of the modified decentralized economy.

Notice that since $u^{\prime \prime}<0, \varphi_{w}<\varphi(a)$ for all $a>\tilde{a}$. That is, in such an environment the planner has to give higher weights to managers with higher ability levels. Any set of weights that is more redistributive implies a higher threshold level, $\bar{a}_{t}$.

\section{Simulations}

In this section we parameterize the economy and solve for its balanced growth path under three scenarios: a decentralized economy, a centrally planned economy, and a weighted 
centrally planned economy where the planner uses the weights described in proposition 4 . The latter scenario is introduced in order to isolate the lobbying effect.

In order to parameterize the model, we need to choose a functional form for the distribution of abilities across the population. We assume that ability levels follow a Pareto distribution. We pick a Pareto distribution because it has the desirable property that the income distribution for entrepreneurs implied by the model is also Pareto. Furthermore, the existing literature reports that a Pareto distribution is a good approximation for the upper tail of the distribution of income (see for instance Levy, 2003 and Steindl, 1965). Given that in our model all workers earn the same labor income, we believe this is a reasonable distribution to consider. The Pareto distribution has two parameters: a location parameter, $a_{m}$, that determines the lowest value with a positive probability of occurring and a shape parameter, $s$, that determines the thickness of the tail of the distribution. The density function is given by:

$$
g(a)=\left\{\begin{array}{cc}
0 & a<a_{m} \\
\frac{s a_{m}^{s}}{a^{s+1}} & a \geq a_{m}
\end{array} .\right.
$$

We take the support of abilities to be $S=[1, \infty)$, which implies that $a_{m}=1$.

Detailed and accurate data on centrally planned economies are hard to obtain. Therefore, we consider parameter values so that the balanced growth path of the decentralized economy matches long-run trends for the U.S. economy. We normalize $\ell=1$. We choose a discount factor $\beta=.95$, intertemporal elasticity of substitution of 1.25 , which implies $\sigma=.2$, and a depreciation rate of 6 percent, all in line with existing literature. The rest of the parameters are jointly chosen in order to match the following long-run features of the U.S. economy: a growth rate of output per working-age person of 
2 percent $(\eta=.02)$, a capital share of income of $1 / 3$, a share of employment in entrepreneurial activities of 20 percent and a Gini coefficient for the distribution of earnings of $.35 .^{13}$ Table 2 presents the list of parameters and their corresponding values. The Appendix shows in more detail the relationship between the data and the parameters. Given the model's parameterization, the distribution of abilities is plotted in Figure 1. Table 3 presents the results of the simulations. The first two columns present the balanced growth path values for the decentralized and centrally planned economies. Values for the weighted centrally planned economy are in the third column. The variables for the decentralized economy are listed only for informational purposes, since we have parameterized the model so that the decentralized economy matched the data perfectly in all the reported dimensions. From Table 3 we observe that the market economy has higher TFP and GDP growth than the centrally planned economy, with differences on the order of 4 . The lower growth of the centrally planned economy comes from two sources: first, the reduction in the time that each entrepreneur spends in entrepreneurial activities, due to the need to spend time lobbying for resources; and, second, the incentives from greater redistribution that result from treating all individuals equally. We can derive the magnitude of the lobbying effect by comparing these economies with the weighted centrally planned economy (column 3). We observe that the reduction in the time spent in entrepreneurial abilities is responsible for 87 percent of the difference in output growth between the decentralized and the centrally planned economies. Only 13 percent of the difference is due to the change in the fraction of

\footnotetext{
${ }^{13}$ We adjust the Gini coefficient for household labor earnings in Díaz-Giménez et al. (1997) to a model where the first 80 percent of the population (workers) are identical. The resulting value is .46 . We further adjust this coefficient downwards in order to get an estimate of the Gini coefficient for individual labor earnings.
} 
entrepreneurs in the economy caused by the fact that the centralized economy is a more egalitarian regime. This implies that the inefficiencies associated with the time spent in lobbying activities are responsible for most of the differences in TFP and GDP growth between our decentralized and centrally planned economies. The lower time spent by managers in productive activities reduces their contribution to the stock of managerial knowledge and, therefore, it reduces growth rates. Regarding differences in labor earnings' inequality, the Gini coefficients for the decentralized and the weighted centrally planned economies are the same. Therefore, all the reduction in inequality is driven by the leadership's allocation of income across ability levels. Lorenz curves representing the distribution of labor earnings are depicted in Figure 2.

Income Gini coefficients for a large number of countries are reported by Deininger and Squire (1996). ${ }^{14}$ Our results are consistent with their observation of lower Gini coefficients in Eastern European countries compared to the U.S. (.26 versus .35 in the U.S.). Regarding magnitudes, the Gini coefficients in our simulations are smaller than the ones reported by Deininger and Squire (1996). In the context of our framework, this may be an indication that the leadership of actual centrally planned economies did not behave according to a completely egalitarian welfare function.

Notice also that the capital-output ratio is higher in the centrally planned economy, as the planner supplements the lower productivity with higher levels of capital. This result is also consistent with evidence from socialist economies.

In this exercise we have parameterized the economy using US data and assuming that there is no redistribution of earnings in the decentralized economy. In doing this we are

\footnotetext{
${ }^{14}$ Díaz-Giménea et al. (1997) report a high correlation between labor earnings and income, with the distribution of labor earnings being more unequal than the distribution of income.
} 
underestimating the dispersion of the distribution of abilities, since redistribution schemes reduce the Gini coefficient. ${ }^{15}$ In the next section we address this issue by performing a sensitivity analysis exercise on the shape parameter $s$ of the Pareto distribution, which determines the dispersion of the distribution.

\subsection{Sensitivity analysis}

The most important free parameter in our parameterization exercise is the parameter $\mu$ that appears in the law of motion of the stock of managerial knowledge $\lambda_{t}$ and that specifies the depreciation of managerial knowledge: $\lambda_{t+1}-\lambda_{t}=\lambda_{t}\left(\gamma \ell M\left(\tilde{a}_{t}\right)-\mu\right)$.

Table 4 presents the TFP and GDP growth rates as well as the Gini coefficient for the centrally planned economy under different values of the parameter $\mu$. Since $\mu$ is calibrated jointly with other parameters, changing $\mu$ implies a recalibration of the whole set of parameters in order for the decentralized economy to match the long-run trends of the U.S. economy. Given that the decentralized economy is calibrated to match U.S. trends, the values of these variables will not change with a change in $\mu$, and are the same as in Table 3. We observe that the TFP growth rate for the centrally planned economy decreases as $\mu$ increases, and it becomes negative for slightly positive values of $\mu$. In particular, for slightly positive values of $\mu$ long run TFP and GDP growth rates become negative. Convergence to such growth rates is not sustainable, which is a possible explanation of the reason why centrally planned regimes have been abandoned by most countries.

\footnotetext{
${ }^{15}$ We thank an anonymous referee for making this suggestion to us.
} 
Another important parameter of the model is the shape parameter $s$, which determines the dispersion of the distribution of abilities. A higher dispersion of abilities makes redistribution more important, since it increases the difference between the ability thresholds in both economies ( $\tilde{a}$ and $\bar{a}$ ). In order to understand the quantitative effects of this parameter, we reparameterize the model using a shape parameter of 1.2 and 1.1 (compared to the 1.35 used in the original parameterization), which imply Gini coefficients on labor earnings of .49 and .79 respectively ( 40 and 125 percent higher than in the original parameterization). We obtain that the time spent in lobbying changes to 60 and 51 percent respectively, with the lobbying effect being responsible for 83 and 79 percent (respectively ) of the decrease in output. We observe that these numbers, even though they are smaller than the original ones, are still in the 80 percent range.

\section{Conclusion}

In this paper we present a framework for comparing decentralized and centrally planned economies and we use it to analyze the different long-run economic performance of the two types of regimes. In our framework, the long-run growth rates of output and productivity are determined by the growth of the stock of managerial knowledge, which in turn depends on the share of the population involved in entrepreneurial activities and on the time that they spend in those activities.

We analyze the effect of two characteristics of centrally planned economies on their growth performance. First, in centrally planned economies factors of production are distributed by the leadership to the firms' managers through a contest that uses up some 
of the managers' productive effort. Second, the leadership is egalitarian, in the sense that it treats individuals with different abilities equally. We show that these two features reduce the fraction of people becoming entrepreneurs/managers, as well as their entrepreneurial effort which, in turn, reduces long-run output and TFP growth. Our model also predicts that the centrally planned economies should have lower income inequality and slightly higher capital-output ratios, both features consistent with the experiences of these regimes.

We also analyze the effect on economic performance of each of these two characteristics separately. We find that the reduction in entrepreneurial effort accounts for about 85 percent of the decrease in long-run growth rates, whereas the egalitarian leadership accounts for the difference in income inequality between both regimes.

In this paper we take the stand that entrepreneurial/managerial activity is essential for long-run economic growth. By reducing entrepreneurial effort in their countries and closing themselves off to new ideas and technologies developed in market-oriented economies, centrally planned economies seriously impaired their ability to sustain longrun growth, contributing perhaps to their regimes' eventual collapse.

The framework developed in this paper is quite general and can be used to analyze issues of economic growth other than those considered here. Our framework introduces a channel through which entrepreneurial activity has long-run economic effects that could be used, for example, to study the growth effects of policies that affect entrepreneurial incentives, such as industrial regulation and taxation.

This paper is about long-run trends. Two important issues regarding transitions are not analyzed there. First, we do not explain the transition from high growth rates of output 
and TFP in the 1960 s to increasingly lower growth rates in the 1970 s and 1980 s experienced by centrally planned economies. Inefficiencies built into the system that did not allow for the implementation of new ideas that naturally come with free markets and competition are probably crucial to this evolution. Papers like Atkeson and Kehoe (1995) and Chu (2001) introduce such inefficiencies in decentralized economies. Similar techniques could be used in this framework. Second, our paper does not address the issue of transitioning from one economic regime to the other. This is the subject of further research. 


\section{References}

Atkeson, A., Kehoe, P. J., 1995. Industry Evolution and Transition: Measuring Investment in Organization Capital, Federal Reserve Bank of Minneapolis, Staff Report 201.

Baik, K. H., 1998. Difference-form Contest Success Functions and Effort Levels in Contests, European Journal of Political Economy 14, 685-701.

Baumol, W. J., 1990. Entrepreneurship: Productive, Unproductive, and Destructive, Journal of Political Economy 98, 893-921.

Berliner, J. S., 1957. Factory and Manager in the USSR. Harvard University Press, Cambridge, MA.

Berliner, J. S., 1976. The Innovation Decision in Soviet Industry. The MIT Press, Cambridge, MA.

Berliner, J. S., 1999. The Economics of the Good Society. Blackwell Publishers, Malden.

Bergson, A., 1989. Planning and Performance in Socialist Economies: The USSR and Eastern Europe. Unwin Hyman, Boston, MA.

Brixiová, Z., Bulíř, A. , 2003. Output Performance under Central Planning: A Model of Poor Incentives. Economic Systems 27, 27-39.

Chu, T., 2001. Exit Barriers and Economic Stagnation, unpublished manuscript, EastWest Center.

Deininger, K., Squire, L., 1996. A New Data Set and Measure of Income Inequality, World Bank Economic Review 10: 565-591.

De-Navas-Walt, C., Cleveland, R., 2002. Money Income in the United States: 2001, Current Population Reports P60-218, U.S. Census Bureau, Washington D.C: U.S. Government Printing Office.

Díaz-Giménez, J., Quadrini, V., Ríos-Rull, J. V., 1997. Dimensions of Inequality: Facts on the U.S. Distributions of Earnings, Income, and Wealth, Federal Reserve Bank of Minneapolis Quarterly Review 21, 3-21.

Easterly, W., Fisher, S. 1995. The Soviet Economic Decline, The World Bank Economic Review 9, 341-371.

Hirshleifer, J., 1989. Conflict and Rent-Seeking Success Functions, Ratio vs. Difference Models of Relative Success, Public Choice 63, 101-112. 
Hsieh, C. T., Klenow, P. J., 2007. Misallocation and Manufacturing TFP in China and India, NBER working paper, 13290.

Levy, M., 2003. Are Rich People Smarter?, Journal of Economic Theory 110, 42-64.

Lucas, R., 1978. On the Size Distribution of Business Firms, Bell Journal of Economics 9, 508-523.

Madrid-Aris, M., 1997. Growth and Technological Change in Cuba, Cuba in Transition 7, 216-228.

Murphy, K. M., Shleifer, A., Vishny, R. W., 1991. The Allocation of Talent: Implications for Growth, Quarterly Journal of Economics 106, 503-530.

Olson, M., 1982. The Rise and Decline of Nations. Yale University Press, New Haven, CT.

Restuccia, D., Rogerson, R., 2007. Policy Distortions and Aggregate Productivity with Heterogeneous Plants, NBER working paper 13018.

Roberts, P. C., 1990. Alienation and the Soviet Economy: The Collapse of the Socialist Era, The Independent Institute.

Roberts, B. W., Rodriguez, A., 1997. Economic Growth under a Self-Interested Central Planner and Transition to a Market Economy, Journal of Comparative Economics 24, 121-139.

Steindl, J., 1965. Random Processes and the Growth of Firms -A Study of the Pareto Law. Charles Griffin and Company, London. 


\section{APPENDIX}

\section{Characterization of equilibrium of the decentralized economy}

In this section of the appendix we list the equations that characterize the equilibrium of a decentralized economy where entrepreneurs spend a fraction $x \in[0,1]$ in productive activities and with an initial distribution of capital stocks $\left\{k_{0}(a)\right\}$, for $a \in S$.

First order conditions for entrepreneurs:

$$
\begin{gathered}
\kappa_{t}(a)=\frac{\alpha}{1-\alpha} \frac{w_{t}}{r_{t}} \\
\Delta_{t}=\left[\theta\left(\frac{\alpha}{r_{t}}\right)^{\alpha}\left(\frac{1-\alpha}{w_{t}}\right)^{1-\alpha}\right]^{1 /(1-\theta)} \\
n_{t}(a)=\ell a \frac{1}{h} \lambda_{t}^{1 /(1-\theta)} \kappa_{t}^{-\alpha} \Delta_{t}, \quad a \in \tilde{S}_{t} \\
k_{t}(a)=\ell a \lambda_{t}^{1 /(1-\theta)} \kappa_{t}^{1-\alpha} \Delta_{t}, \quad a \in \tilde{S}_{t} \\
y_{t}(a)=\ell a \lambda_{t}^{1 /(1-\theta)} \Delta_{t}^{\theta}, \quad a \in \tilde{S}_{t} \\
\pi_{t}(a)=(1-\theta) y_{t}(a), \quad a \in \tilde{S}_{t}
\end{gathered}
$$

Individual with ability $\tilde{a}_{t}$ is indifferent between being an entrepreneur and a worker:

$$
\frac{\tilde{a}_{t} G\left(\tilde{a}_{t}\right)}{M\left(\tilde{a}_{t}\right)}=\frac{\theta(1-\alpha)}{(1-\theta)}
$$

First order conditions for the consumer:

$$
\begin{gathered}
\frac{c_{t}(a)}{c_{t+1}(a)}=\left[\beta\left(1+r_{t+1}^{b}\right)\right]^{1 /(\sigma-1)}, \quad a \in S \\
r_{t}^{b}=r_{t}-\delta
\end{gathered}
$$




$$
m_{t}(a)=\max \left\{w_{t}, \pi_{t}(a)\right\}, \quad a \in S
$$

Consumer's budget constraint:

$$
c_{t}(a)+b_{t+1}(a)=m_{t}(a)+\left(1+r_{t}^{b}\right) b_{t}(a), \quad a \in S
$$

Aggregate variables:

$$
\begin{gathered}
M\left(\tilde{a}_{t}\right) \equiv \int_{\tilde{S}_{t}} a d G(a) \\
K_{t} \equiv N \int_{\tilde{S}_{t}} k_{t}(a) d G(a)=N \ell \lambda_{t}^{1 /(1-\theta)} \kappa_{t}^{1-\alpha} \Delta_{t} M\left(\tilde{a}_{t}\right) \\
L_{t} \equiv N \int_{\tilde{S}_{t}} n_{t}(a) d G(a)=\frac{N}{h} \ell \lambda_{t}^{1 /(1-\theta)} \kappa_{t}^{-\alpha} \Delta_{t} M\left(\tilde{a}_{t}\right) \\
Y_{t} \equiv N \int_{\tilde{S}_{t}} y_{t}(a) d G(a)=N \ell \lambda_{t}^{1 /(1-\theta)} \Delta_{t}^{\theta} M\left(\tilde{a}_{t}\right)
\end{gathered}
$$

Feasibility conditions:

$$
\begin{gathered}
N G\left(\tilde{a}_{t}\right)=L_{t} \\
N \int_{S} b_{t}(a) d G(a)=K_{t} \\
N \int_{S}\left[c_{t}(a)+b_{t+1}(a)-(1-\delta) b_{t}(a)\right] d G(a)=Y_{t}
\end{gathered}
$$

Evolution of the stock of knowledge:

$$
\frac{\lambda_{t+1}-\lambda_{t}}{\lambda_{t}}=\gamma \ell M\left(\tilde{a}_{t}\right)-\mu
$$

\section{Characterization of equilibrium of the centrally planned economy}

In this section of the appendix we list the equations that characterize the equilibrium of a weighted centrally planned economy with an initial distribution of capital stocks $\left\{k_{0}(a)\right\}$, 
and individual weights $\varphi(a)$, for $a \in S$. By setting $\varphi(a)=1$ for $a \in S$ we obtain the equations that characterize the centrally planned economy.

From the first order conditions for the planner's problem:

$$
\begin{gathered}
\beta^{t} N u^{\prime}\left(m_{t}\right) \int_{S \backslash \bar{S}_{t}} \varphi(a) d G(a)-\varsigma_{t}\left[N G\left(\bar{a}_{t}\right)-\frac{g\left(\bar{a}_{t}\right) Y_{t}}{\tau_{t}}\left(\frac{\theta(1-\alpha)}{G\left(\bar{a}_{t}\right)}-(1-\theta) \frac{\bar{a}_{t}}{M\left(\bar{a}_{t}\right)}\right)\right]=0 \\
\varsigma_{t}=\frac{\beta^{t}\left[\bar{a}_{t} u^{\prime}\left(m_{t}\right) \int_{S \backslash \bar{S}_{t}} \varphi(a) d G(a)+\int_{\bar{S}_{t}} \varphi(a) u^{\prime}\left(\tau_{t} a\right) a d G(a)\right]}{\bar{a}_{t} G\left(\bar{a}_{t}\right)+M\left(\bar{a}_{t}\right)} \\
\frac{\varsigma_{t}}{\varsigma_{t+1}}=1-\delta+\alpha \theta \frac{Y_{t+1}}{K_{t+1}}
\end{gathered}
$$

Feasibility conditions:

$$
\begin{gathered}
N\left[m_{t} G\left(\bar{a}_{t}\right)+\tau_{t} M\left(\bar{a}_{t}\right)\right]+K_{t+1}-(1-\delta) K_{t}=Y_{t} \\
Y_{t}=\lambda_{t}(1-\theta)^{1-\theta} \ell^{1-\theta} N^{1-\theta} M\left(\tilde{a}_{t}\right)^{1-\theta} K_{t}^{\alpha \theta} H_{t}^{(1-\alpha) \theta} \\
H_{t}=N G\left(\bar{a}_{t}\right)
\end{gathered}
$$

Individuals of type $\tilde{a}_{t}$ are indifferent between being managers or workers

$$
\bar{a}_{t}=m_{t} / \tau_{t}
$$

Evolution of the stock of knowledge:

$$
\frac{\lambda_{t+1}-\lambda_{t}}{\lambda_{t}}=\gamma(1-\theta) \ell \int_{S_{t}} \operatorname{adG}(a)-\mu
$$

Individual variables:

$$
\begin{gathered}
y_{t}(a)=\lambda_{t} a(1-\theta)^{1-\theta} \ell^{1-\theta} \frac{K_{t}^{\alpha \theta} H_{t}^{(1-\alpha) \theta}}{N^{\theta} M\left(\bar{a}_{t}\right)^{\theta}}, \quad a \in \bar{S}_{t} \\
m_{t}(a)=\left\{\begin{array}{ll}
m_{t} & \text { if } a \leq \bar{a}_{t} \\
\tau_{t} a & \text { if } a>\bar{a}_{t}
\end{array}, \quad a \in S\right.
\end{gathered}
$$




$$
c_{t}(a)=m_{t}(a), \quad a \in S
$$

\section{Proofs of the propositions}

Proof of proposition 2. Assume that we have an equilibrium of the decentralized economy. Define an equilibrium of the economy with a representative consumer in the following way (here $\hat{v}$ represents a generic variable of the economy with a representative consumer): $\hat{c}_{t}=\int_{S} c_{t}(a) d G(a), \hat{m}_{t}=\int_{S} m_{t}(a) d G(a), \hat{b}_{t}=\int_{S} b_{t}(a) d G(a), \hat{K}_{t}=K_{t}, \hat{L}_{t}=L_{t}$ $\hat{r}_{t}=r_{t}, \hat{r}_{t}^{b}=r_{t}^{b}, \hat{w}_{t}=w_{t}, \hat{\kappa}_{t}=\kappa_{t}, \hat{\lambda}_{t}=\lambda_{t}$

It is easy to see that with these definitions the feasibility conditions and the first order conditions for the consumer are satisfied. Define $A_{t} \equiv \hat{\lambda}_{t} \ell N^{1-\theta} M\left(\tilde{a}_{t}\right)^{1-\theta}$ and $\hat{H}_{t}=\hat{L}_{t}$. The first order conditions for the single producer are:

$$
\begin{aligned}
& \hat{r}_{t}=\alpha \theta A_{t} \hat{K}_{t}^{\alpha \theta-1} \hat{H}_{t}^{(1-\alpha) \theta} \\
& \hat{w}_{t}=(1-\alpha) \theta A_{t} \hat{K}_{t}^{\alpha \theta} \hat{H}_{t}^{(1-\alpha) \theta-1},
\end{aligned}
$$

which are satisfied, given (41), (42), and (54).

Proof of proposition 3: The proof is by contradiction. Assume first that $\bar{a}_{t}<\tilde{a}$. The term in brackets in equation (60) is strictly decreasing and equal to zero at $\tilde{a}$. Therefore, it is positive at $\bar{a}_{t}$. Therefore, since equation (60) is satisfied at $\bar{a}_{t}$, it has to be the case that $\beta^{t} u^{\prime}\left(m_{t}\right)-\varsigma_{t}<0$. Using (61) this implies that

$$
u^{\prime}\left(m_{t}\right) M\left(\bar{a}_{t}\right)<\int_{\bar{S}_{t}} u^{\prime}\left(\tau_{t} a\right) a d G(a)
$$

But: 
$\int_{\bar{S}_{t}} u^{\prime}\left(\tau_{t} a\right) a d G(a)=\int_{\bar{S}_{t}} u^{\prime}\left(\frac{m_{t}}{\bar{a}_{t}} a\right) \operatorname{adG}(a) \leq u^{\prime}\left(m_{t}\right) M\left(\bar{a}_{t}\right)$,

where the last inequality holds since $u^{\prime}$ is strictly decreasing and $a \geq \bar{a}_{t}$ for all $a \in \bar{S}_{t}$.

This contradicts the previous inequality.

Assume now that $\bar{a}_{t}=\tilde{a}$. The term in brackets in (60) is then zero. Therefore, it has to be the case that $u^{\prime}\left(m_{t}\right) M\left(\bar{a}_{t}\right)=\int_{\bar{S}_{t}} u^{\prime}\left(\tau_{t} a\right) a d G(a)$. Following the same argument above, this is only true if $\bar{S}_{t}=\left\{\bar{a}_{t}\right\}$, that is, if the distribution of abilities among entrepreneurs is degenerate. Given our assumptions on the distribution of abilities, this cannot be the case.

Proof of proposition 4: The key of the proof is to find a distribution of capital across ability levels for which consumption is the same for all workers and is linear in ability for all entrepreneurs. Let $\hat{v}$ be a generic equilibrium price or aggregate variable for a balanced growth path of the representative version of the model economy with $\hat{\ell}=(1-\theta) \ell$. Define $\bar{a}=\tilde{a}$, and $B=\tilde{a} G(\tilde{a})+M(\tilde{a})$. Define:

$$
m=\frac{\tilde{a}}{B} \hat{c}_{0}
$$

and

$$
\tau=m a
$$

It is easy to see that with these definitions all the conditions for the equilibrium of the centrally planned economy are satisfied. Furthermore, the disaggregated consumption levels: 


$$
c_{0}(a)= \begin{cases}\tau a & a \geq \tilde{a} \\ m & a<\tilde{a}\end{cases}
$$

are initial consumption levels corresponding to a balanced growth path of the decentralized economy with distribution of capital:

$$
k_{0}(a)=\left\{\begin{array}{ll}
\frac{a}{B} & a \geq \tilde{a} \\
\frac{\tilde{a}}{B} & a \leq \tilde{a}
\end{array} .\right.
$$

\section{Parameterization: relationship between data and parameter values}

Parameters $\beta, \delta, a_{m}, \ell, \sigma$, and $\mu$ are exogenously given. In order to pin down the other parameters of the model we use the following algorithm:

- Pick a value for $s$

- Get $\tilde{a}$ by setting $G(\tilde{a})=.8$, which is consistent with a 20 percent of the population being entrepreneurs, in the Pareto distribution.

- Get $\theta$ using equation (47)

- Compute $B \equiv \frac{\tilde{a} G(\tilde{a})}{M(\tilde{a})}$

- Set $n \equiv \alpha \theta$, the capital share, to $1 / 3$

- Solve for $\theta$ in equation (47)

- Get $\gamma$ from equation (59)

- Set the growth rate of output to 2 percent

- Solve for $\gamma$ in equation (59)

- Find the Gini coefficient implied by the decentralized economy, $g$ 
- Adjust the parameter $s$ until the Gini coefficient is equal to .35

\section{General framework with distinct managerial and lobbying abilities}

Consider a generalized version of the model where individuals are characterized by a pair $\left(a, a_{l}\right) \in S \times S_{l}$ representing, respectively, their managerial and lobbying abilities. Let $G\left(a, a_{l}\right)$ be the joint distribution function of both types of abilities, with support $S \times S_{l}$. The decentralized economy behaves in the same way as in the simple model, since there is no value to lobbying.

In the centrally planned economy, the quantity of resources that an entrepreneur receives from the leadership depends only on his lobbying ability (and not on his managerial ability). Equation (25) becomes:

$$
z\left(a, a_{l}\right)=\frac{(1-x) a_{l}}{v}
$$

where $v=N \int_{S \times S_{l}}\left(1-x\left(a, a_{l}\right)\right) a_{l} d G\left(a, a_{l}\right)$ is the total efficiency units of lobbying. As in the simple version of the model, all managers devote the same amount of time, $x\left(a, a_{l}\right)=1-\theta$, to productive activities.

An individual $\left(a, a_{l}\right)$ who chooses to be a manager produces output

$$
y_{t}\left(a, a_{l}\right)=\frac{\hat{B}_{t} a^{1-\theta} a_{l}^{\theta}}{v_{t}^{\theta}}
$$

where $\hat{B}_{t}=\lambda_{t} \ell^{1-\theta}(1-\theta)^{1-\theta} \theta^{\theta} K^{\alpha \theta} H^{(1-\alpha) \theta}$. 
Notice that $\left.y_{t}\left(a, a_{l}\right) / y_{t}\left(a^{\prime}, a_{l}^{\prime}\right)=a^{1-\theta} a_{l}^{\theta} /\left(\left(a^{\prime}\right)^{1-\theta} a_{l}^{\prime}\right)^{\theta}\right)$ is different from $a / a^{\prime}$ as long as $a_{l} / a_{l}^{\prime} \neq a / a^{\prime}$. Therefore, unless there is perfect correlation between both abilities, the allocation of resources across managers in the centralized economy is not efficient.

An individual with abilities $\left(a, a_{l}\right)$ becomes a manager if $\bar{\tau}_{t} y_{t}\left(a, a_{l}\right) \geq \bar{m}_{t}$, or:

$$
\frac{\bar{a}^{1-\theta}}{v_{t}^{\theta}}=\frac{\bar{m}_{t}}{\bar{\tau}_{t} B_{t} a_{l}^{\theta}},
$$

which defines a threshold function $\bar{a}\left(a_{l}\right)$ Assume that the distribution scheme given by the leadership has the same structure as in the simple model:

$$
m_{t}\left(a, a_{l}\right)=\left\{\begin{array}{ll}
\bar{m}_{t} & \text { if } a \leq \bar{a}\left(a_{l}\right) \\
\bar{\tau}_{t} y_{t}\left(a, a_{l}\right) & \text { if } a>\bar{a}\left(a_{l}\right)
\end{array},\right.
$$

which can be written as:

$$
m_{t}\left(a, a_{l}\right)=\left\{\begin{array}{ll}
m_{t} & \text { if } a \leq \bar{a}\left(a_{l}\right) \\
\tau_{t} a^{1-\theta} a_{l}^{\theta} & \text { if } a>\bar{a}\left(a_{l}\right)
\end{array} .\right.
$$

The leadership's problem becomes:

$$
\begin{array}{ll}
\max _{m_{t}, \tau_{t}, K_{t+1}} \int_{S \times S_{l}} \sum_{t=0}^{\infty} \beta^{t} N u\left(m_{t}\left(a, a_{l}\right)\right) d G\left(a, a_{l}\right) \\
\text { s.t. } \\
\quad N\left[m_{t} G_{l}+\tau_{t} M_{l}\right]+K_{t+1}-(1-\delta) K_{t}=Y_{t} \\
Y_{t}=\frac{\lambda_{t}(1-\theta)^{1-\theta} \theta^{\theta} \ell^{1-\theta} M_{l}^{1-\theta} K_{t}^{\alpha \theta} H_{t}^{(1-\alpha) \theta},}{v_{t}^{\theta}} \\
H_{t}=N G_{l} \\
\bar{a}_{t}\left(a_{l}\right)=\left(m_{t} / \tau_{t}\right)^{1 /(1-\theta)} a_{l}^{-\theta /(1-\theta)}
\end{array}
$$

where 


$$
\begin{aligned}
& G_{l}=\int_{S_{l}} \int_{S \backslash \bar{S}_{t}\left(a_{l}\right)} d G\left(a, a_{l}\right) \\
& M_{l}=\int_{S_{l}} \int_{\bar{S}_{t}\left(a_{l}\right)} a^{1-\theta} a_{l}^{\theta} d G\left(a, a_{l}\right) \\
& \bar{S}_{t}\left(a_{l}\right)=\left\{a \in S \mid a \geq \bar{a}_{t}\left(a_{l}\right)\right\}
\end{aligned}
$$

This problem is more complicated to solve than the one described in the paper, since it involves solving for a managerial ability threshold function (each level of lobbying ability has a different managerial threshold).

In order to illustrate how the solution to this more general problem may differ from the case where we do not distinguish between managerial and lobbying ability, consider an extreme example where all individuals have the same lobbying ability, $a_{l}=1$. In this case all managers will receive the same share of endowments, $z=\theta / v^{\theta}$. In this example, the managers are still the individuals with the highest managerial ability. Table 5 compares the results of this new version of the model with the ones in table 3 (keeping the parameter values unchanged). Notice that the centrally planned economy with constant lobbying ability has higher TFP and output growth than the centrally planned economy with proportional lobbying ability. This result is surprising at first glance, since conventional wisdom would suggest that adding another distortion should further worsen the economy. Two offsetting factors are at play here: first, resources are not distributed efficiently across managers, having a negative effect on growth. Second, the egalitarian distribution of resources increases the fraction of managers in the economy, increasing managerial activity and having a positive effect on growth. ${ }^{16}$

\footnotetext{
${ }^{16}$ Since resources are not tied to managerial ability, less able individuals are able to become managers given that they receive a higher fraction of resources than they would if resources were linked to managerial ability.
} 
The Gini coefficient is significantly lower than in the original economy, driven mainly by the fact that income across managers is now more equal. Given that in the centrally planned economy with identical lobbying ability the leadership does not distribute resources efficiently among entrepreneurs, proposition 4 does not hold and it is not straight forward to separate the effects of lobbying from the other inefficiencies in this economy. The inefficiencies in this centralized economy have big growth effects: even though the proportion of managers is closer to that of the decentralized economy (managerial activity does not decrease a lot), its output and TFP growth rates are much lower, and quite similar to the ones in the centrally-planned economy with proportional lobbying ability. 
Table 1 - Growth Rates of Real per Capita Output

\begin{tabular}{|c|c|c|c|c|}
\hline \multicolumn{5}{|c|}{ (percent) } \\
\hline & $1950-60$ & $1960-70$ & $1970-80$ & 1980-88 \\
\hline USSR, GNP ${ }^{1}$ & 5.7 & 3.9 & 3.6 & 1.2 \\
\hline USSR, NMP & 8.2 & 6.3 & 4.6 & 2.8 \\
\hline \multicolumn{5}{|l|}{ Czechoslovakia, Hungary, } \\
\hline Poland \& Yugoslavia, NMP ${ }^{2}$ & 6.4 & 4.8 & 4.5 & 0.9 \\
\hline Cuba, GMP ${ }^{3}$ & & 0.7 & 5.2 & 2.7 \\
\hline USA, GDP ${ }^{4}$ & 1.7 & 2.9 & 2.1 & 2.5 \\
\hline
\end{tabular}

${ }^{1}$ GNP and NMP growth rates from Easterly and Fisher (1995), population growth rates calculated from data in Mitchell (1992). Last period covers 1980-87.

${ }^{2}$ Based on calculations from data in Mitchell (1992). Average growth rates are unweighted.

${ }^{3}$ GMP is Gross Material Product. Madrid-Aris (1997).

${ }^{4}$ Bureau of Economic Analysis.

Table 2. Parameter values

\begin{tabular}{|c|c|c|c|c|c|c|c|c|c|}
\hline$\beta$ & $\sigma$ & $a_{m}$ & $s$ & $\delta$ & $\theta$ & $\alpha$ & $\gamma$ & $\mu$ & $\ell$ \\
\hline .95 & .2 & 1 & 1.35 & .06 & .67 & .49 & .005 & 0 & 1 \\
\hline
\end{tabular}


Table 3. Balanced growth path comparisons

\begin{tabular}{|l|c|c|c|}
\hline & Decentralized & Centrally planned & $\begin{array}{c}\text { Weighted } \\
\text { Centrally planned }\end{array}$ \\
\hline TFP growth (\%) & 1.3 & .31 & .44 \\
\hline output growth (\%) & 2 & .46 & .66 \\
\hline Capital/output & 2.55 & 2.83 & 2.79 \\
\hline Entrepreneurs (\%) & 20 & 5 & 20 \\
\hline Gini earnings & .35 & .13 & .35 \\
\hline Lobbying time (\%) & 0 & 67 & 67 \\
\hline
\end{tabular}

Table 4. Sensitivity analysis, parameter $\mu$.

\begin{tabular}{|l|c|c|c|}
\hline & $\mu=0$ & $\mu=0.005$ & $\mu=0.01$ \\
\hline TFP growth (\%) & .31 & -.08 & -.47 \\
\hline GDP growth (\%) & .46 & -.12 & -.7 \\
\hline entrepreneurs (\%) & 5 & 5 & 5 \\
\hline Gini & .124 & .123 & .122 \\
\hline
\end{tabular}


Table A1. Balanced growth path comparisons

\begin{tabular}{|l|c|c|c|}
\hline & Decentralized & $\begin{array}{l}\text { Centrally planned } \\
\text { (proportional } \\
\text { lobbying ability) }\end{array}$ & $\begin{array}{c}\text { Centrally planned } \\
\text { (constant lobbying ability) }\end{array}$ \\
\hline TFP growth (\%) & 1.3 & .31 & .4 \\
\hline output growth (\%) & 2 & .46 & .6 \\
\hline Capital/output & 2.55 & 2.83 & 15 \\
\hline Entrepreneurs (\%) & 20 & 5 & .04 \\
\hline Gini earnings & .35 & .13 & 67 \\
\hline Lobbying time (\%) & 0 & 67 & \\
\hline
\end{tabular}


Figure 1. Distribution of abilities

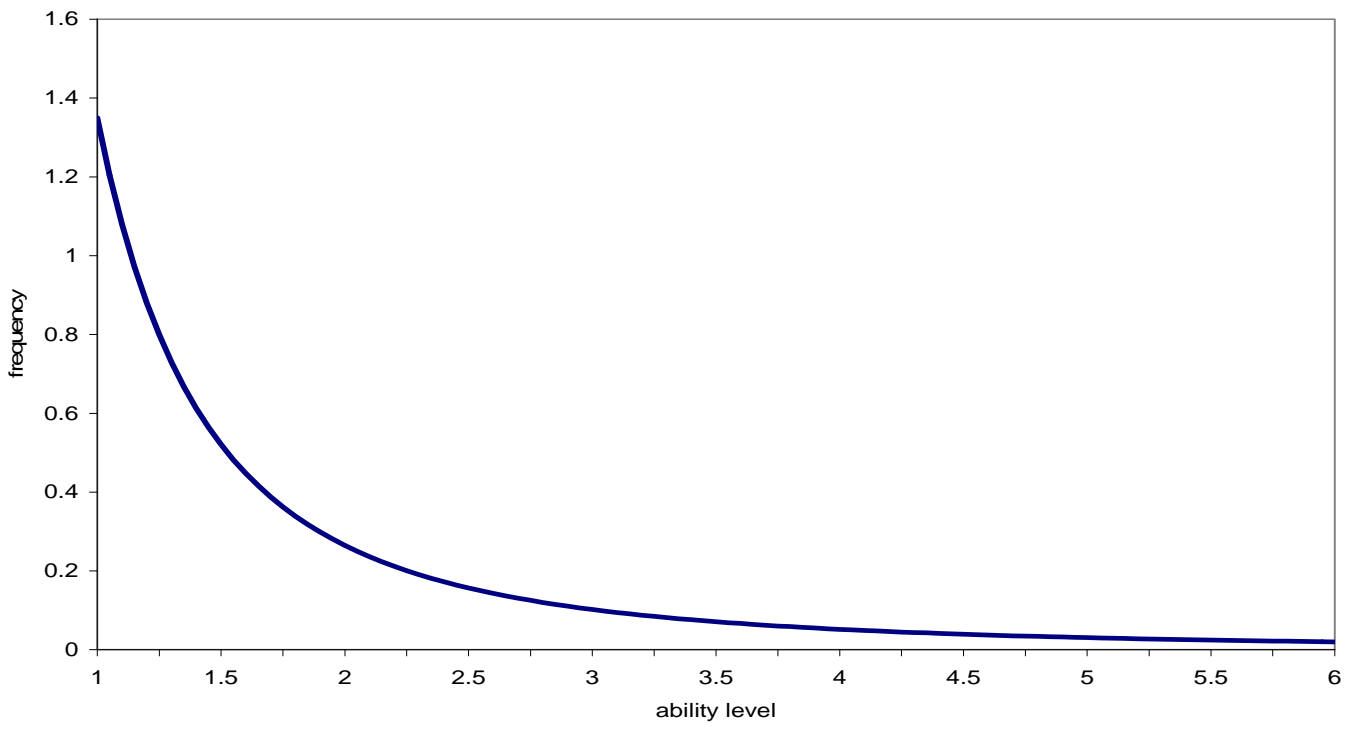

Figure 2: Lorenz curves

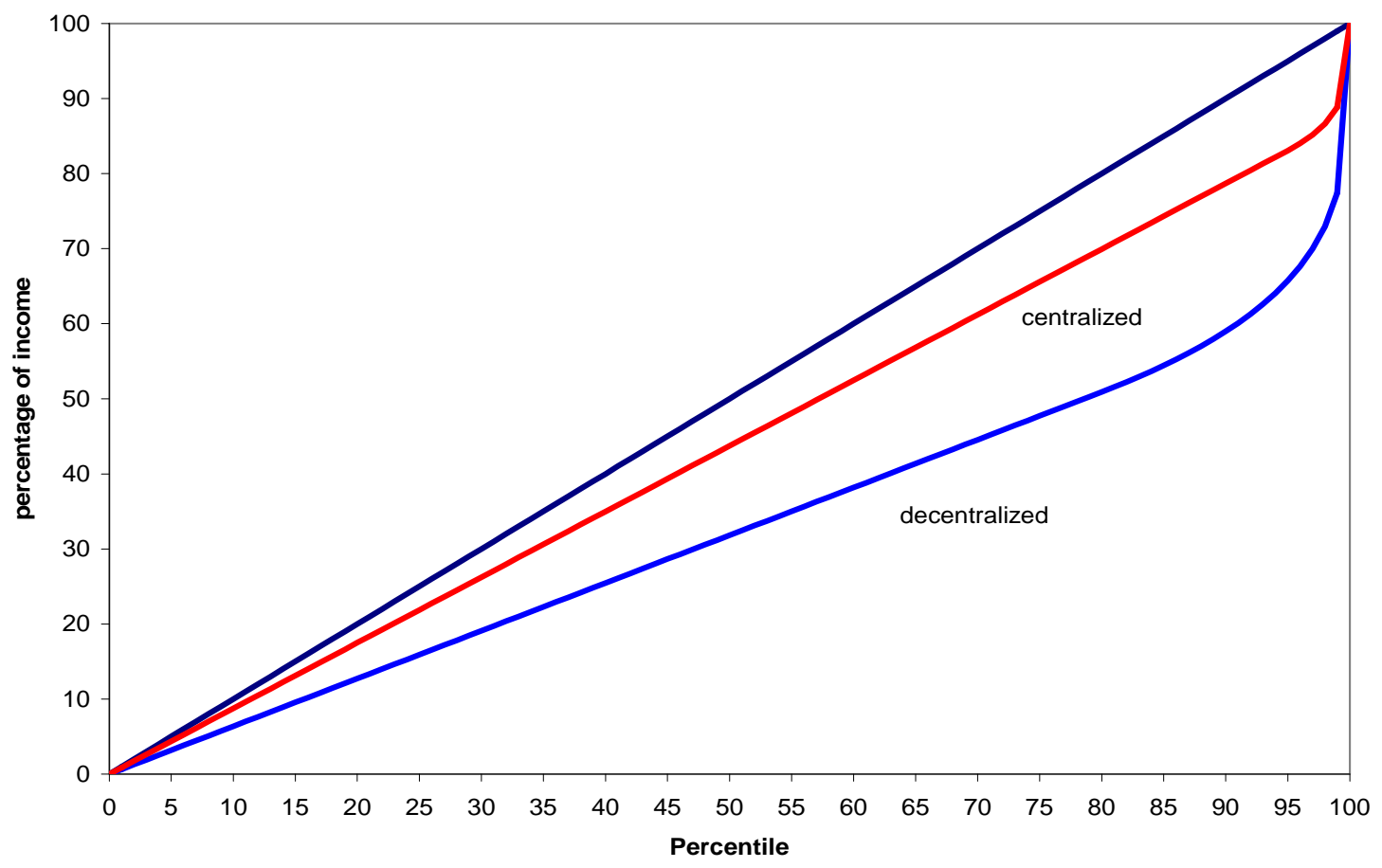

